\title{
RESENHA DO LIVRO: A CASA E O MUNDO LÁ FORA: CARTAS DE PAULO FREIRE PARA NATHERCINHA.
}

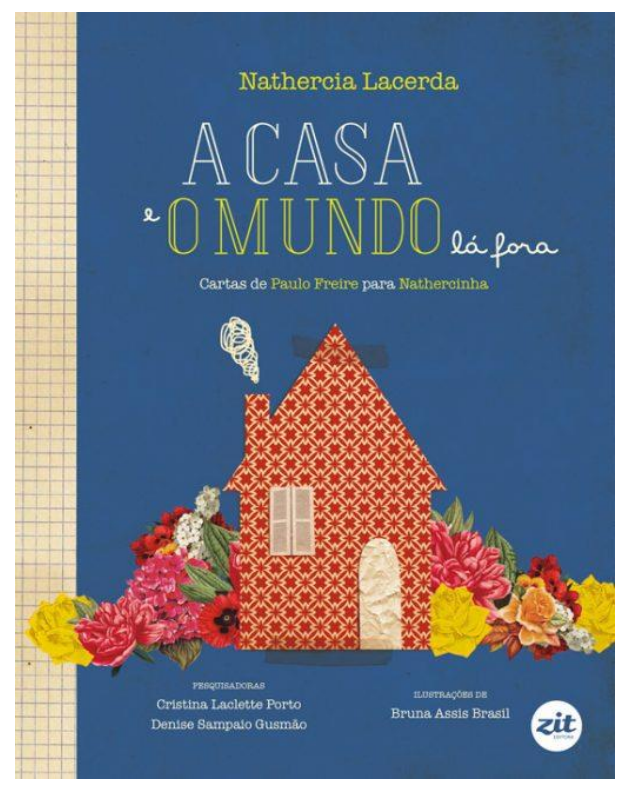

Mariangela Momo $^{1}$

Da casa para o mundo, do mundo para a casa! Foi o que aconteceu comigo durante e após a leitura de uma obra que me auxiliou a experimentar tornar-me um pouco mais humana. Trata-se do livro A casa e o mundo lá fora: cartas de Paulo Freire para Nathercinha, escrito por Nathercia Lacerda e publicado em 2016 pela Zit Editora, indicado para o público infanto-juvenil. Um livro não só para crianças e jovens, mas também para adultos, que nos leva a experimentar o cuidado com o outro, a delicadeza, o conhecer (de um tempo de ditadura no Brasil, uma criança e Paulo Freire nesse tempo, mas também uma família - um tipo de família -, relações familiares, de amor e de amizade, a cidade do Rio de Janeiro, o Brasil, o Chile e outros lugares do mundo), o ser criança e viver a infância em um determinado tempo e lugar, o comunicarse, o dialogar, o sentir-se afetado e afetar, o emocionar-se e emocionar, e o encontro (consigo mesmo, com o outro, com Paulo Freire, Nathercinha, Cristina, Denise, Bruna e Madá).

O livro forneceu-me subsídios e equipou-me para a humanidade (um processo educativo), disparando lembranças de Paulo Freire, recordações do que dele havia lido, estudado e ouvido. Lembranças de um encontro, na verdade, um único encontro que tive com ele e que ele teve conosco, um grupo de estudantes, e não necessariamente comigo. Foi no ano de 1995 na Universidade Federal do Rio Grande do Sul, quando, em um evento no salão de atos da Reitoria, Paulo Freire falaria. O local ficou lotado, e nós, um mero grupo de estudantes (pelo menos foi assim que nos sentimos diante das imponentes autoridades que se fizeram presentes), fomos impedidos de entrar porque já não havia mais espaço, mesmo que nos dispuséssemos a ficar sentados nas escadarias ou em pé. Com o modo

\footnotetext{
1 Pedagoga, Especialista em Educação Infantil e Doutora em Educação pela Universidade Federal do Rio Grande do Sul (UFRGS). Pós-doutora pelo Programa de Pós-Graduação em Educação da Universidade de Brasília (UNB). Atualmente é professora Associada do Centro de Educação da Universidade Federal do Rio Grande do Norte (UFRN).

marimomo@terra.com.br
} 
de pensar de jovens estudantes, sentimo-nos injustiçados, clamamos por Paulo Freire, e ele nos atendeu. No término da sua fala, não sei como, conseguiu que todos nós que havíamos ficado do lado de fora fôssemos recebidos por ele, em um sistema de rodízio, um grupo de cada vez, para com ele dialogar. Não ignorou outros homens por serem jovens estudantes e nos fez sentir respeitados e importantes, já que fomos por ele recebidos e, ainda, na sala da reitora!

Ao ler o livro em questão, lembrei-me dele; eu o reconheci nas cartas que escreveu para Nathercinha e que ela generosamente nos dá a conhecer no livro. Um homem adulto que, mesmo na condição de exílio no Chile, dedica seu tempo, escolhe as palavras certas e capricha na letra (isso quem diz é Madá - Madalena Freire - após realizar a leitura das cartas e escrever uma carta para sua prima em terceiro grau, Nathercia Lacerda, carta que também consta no livro), para efetivamente comunicar-se e encontrar-se (textualmente) com Nathercinha. Aos nove anos de idade, ela escreve para ele pela primeira vez em 1967, desconhecendo sua condição de exílio e motivada, como ela mesma diz, talvez pela curiosidade em saber sobre um país onde caía neve, talvez pela vontade de trocar cartas pela primeira vez, talvez pela saudade de Paulo Freire ou, ainda, porque via as cartas que iam e vinham. Independentemente do que motivou a menina a escrever, o fato é que Paulo Freire não ignorou outro ser humano por ser criança. Por meio de cartas trocadas entre 1967 e 1969, estabeleceu diálogo com esta criança e deu-lhe a conhecer o mundo lá fora, como é possível perceber nas seis cartas que constam na íntegra no livro em dois formatos (digitadas e manuscritas por Paulo Freire e "coladas no livro com fita adesiva" - para mim, este é o efeito das imagens - por Bruna Assis Brasil, a ilustradora). Ele apresenta para a menina o mundo fora do Brasil e o faz de uma forma como quem quer dar a experimentar a brancura da neve da cordilheira dos Andes, as árvores ficando curvadas e branquinhas com a queda da neve, os vários tons das folhas no outono, mas também a falta da chuva que em 1968, em pleno mês de agosto, fez com que a cordilheira ficasse cinzenta, ao invés de branquinha. Além do Chile, dá a conhecer, ainda que brevemente, outras experiências e outros lugares, como Cambridge e Boston; cita Paris, Roma e Genebra e mostra-lhe a lua em 1969 (sua última carta), enviando-lhe uma fotografia do primeiro homem na lua (que também está "colada no livro com fita adesiva”). Como bem analisa Madá as cartas escritas por seu pai para Nathercinha, nas primeiras, Paulo Freire chama a atenção da menina para o mundo diferente onde ele estava, como a natureza, a geografia, as pessoas e a cidade. Vai ampliando o mundo, deixando-o maior do que aquele onde Nathercinha vivia no Rio de Janeiro, com as experiências em família na casa da Urca; depois, pouco a pouco, nas últimas cartas, "vai abrindo o mundo para suas dores, para sua desigualdade" (LACERDA, 2016, p. 83), e recomenda que ao crescer ela não se aparte da criança 
que existe nela. É possível perceber ainda, na última carta, a explicitação de uma relação de confiança entre Paulo Freire e Nathercinha quando ele fornece o seu novo endereço particular para ela, uma criança, escrito com caneta bem clara para manter o máximo de sigilo possível (essa inscrição praticamente não aparece na ilustração do livro, mas consta a informação sobre ela).

Mas não é só Paulo Freire e as suas cartas que nos dão a conhecer e nos possibilitam o processo educativo de tornarmo-nos mais humanos. É a relação de Nathercia Lacerda, a autora do livro, com ele e com suas amigas de invencionices, como ela carinhosamente as chama: Cristina Laclette Porto e Denise Sampaio Gusmão. São os encontros e conversas entre elas que permitem a descoberta do tesouro da infância de Nathercinha - as cartas de Paulo Freire. A partir daí, Cristina e Denise, que quando crianças se imaginavam escavando em áreas remotas do planeta, desejando ser paleontóloga e arqueóloga, respectivamente, e tornando-se historiadora e psicóloga quando adultas, decidiram escavar memórias nas cartas - e isto quem nos conta são elas, logo no início do livro. Uma escavação que se deu nos encontros de Cristina, Denise, Nathercia e também Madá, que participou de alguns, nos quais elas liam as cartas de Paulo Freire, viam fotografias e envelopes da infância de Nathercinha, entre outros documentos, e tinham lembranças, sentimentos e pensamentos disparados. A partir desses encontros, ou nesses encontros, Nathercia Lacerda aceitou o desafio de escrever o livro. Para chegar às cartas de Paulo Freire, precisou antes (de acordo com as seções em que o livro está organizado) passar por seu tempo de menina, pela história de sua família (incluindo uma breve descrição genealógica a partir da qual entendemos que Paulo Freire era seu primo em segundo grau e ela o considerava mais um tio), pelas relações de amor e de amizade dessa família (abrangendo situações de mistério sobre o que realmente aconteceu com alguns amigos da família no período da ditadura militar), por Pernambuco, pela cidade do Rio de Janeiro e pela casa da Urca, onde moravam os avós maternos de Nathercinha e onde ela conheceu Paulo Freire antes de seu exílio.

Como não querer conhecer a casa da Urca e tudo o mais que o livro nos mostra? Aproveitando a situação de estar na cidade do Rio de Janeiro e morando temporariamente em Botafogo, saí de casa, do livro, para o mundo em um domingo de sol para procurar a casa da Urca a partir do caminho descrito no livro. Fui movida, penso eu, pelo texto que li, mas também pelas fotografias que vi (Nathercinha com o irmão no colo na varanda florida da casa da Urca; Nathercinha aparentando ter uns quatro anos de idade, de mão dada com a mãe, grávida, descendo a ladeira de São Sebastião; o Pão de Açúcar e um bondinho na sua direção) e por tantas pistas e evidências da escavação realizada pelas amigas pesquisadoras. Fotografias e imagens de época em preto e branco, incluindo imagens de objetos, acrescidas de detalhes coloridos ou de elementos novos introduzidos por Bruna (como já 
sabem, a ilustradora, faz a composição gráfica da obra parecer uma espécie de diário de memórias de infância repleto de coisas guardadas: cartas, envelopes, fotografias, passaporte, recortes de flores, nuvens, montanhas, pássaros, vestidos, clipes, etc.). Como anunciou Nathercia sobre a casa da Urca de hoje, encontrei-a passando o prédio da antiga TV Tupi, logo no início da ladeira São Sebastião, ao lado do misterioso castelinho, que ainda está lá, assim como a mangueira plantada por sua avó, bem próxima da pedra gigante que compõe o morro do Pão de Açúcar. Pareceu-me, pela vista que tive a partir da rua, que o prédio de três andares e a casa que ficava no térreo continuam com o quintal sem cerca, para os fundos dessa pedra que era o limite das brincadeiras das crianças.

Hoje percebo que minha busca pela casa da Urca não foi para investigar ou constatar se o que Nathercia dizia no livro era verdade; foi para tentar continuar a viver a emoção que senti ao ler o livro, aproximar-me da experiência do ser criança naquele tempo, naquela casa, naquela ladeira que se inicia tão perto do mar. Eu queria mesmo encontrar Nathercinha e Paulo Freire, ouvir o alvoroço daquela família que eu havia encontrado reunida nas páginas do livro. Talvez Nathercia também tenha desejado encontrar Paulo Freire, o da sua infância, ao concluir o livro escrevendo uma carta para ele dos dias de hoje, nos dias de hoje.

Antes dessa carta, porém, ela nos conta como foi o reencontro com Paulo Freire, já adulta, quando em 1979 ele finalmente pôde voltar ao Brasil e não era mais para ela apenas o primo-tioamigo, mas também o grande educador que ela encontrou em algumas oportunidades nos anos seguintes, como em palestras em universidades brasileiras. Nas últimas linhas da carta que escreve 15 anos após o falecimento de Paulo Freire, Nathercia diz: "Aguardo notícias suas em uma folha que cai, em um voo de pássaro ou em um desabrochar de flor em minha janela”. (LACERDA, 2016, p.77). O desejo de notícias, o desejo do encontro e a vontade de comunicação, mesmo diante de (im)possibilidades como o exílio e a morte, demonstram para mim que Nathercinha e Nathercia também não desistem do outro.

Senti-me tocada e, mais uma vez, saí das páginas do livro e me pus a escrever uma carta para uma amiga distante que já está em um estágio bem adiantado de uma doença degenerativa que não afeta o raciocínio intelectual, mas que, no caso dela, já não lhe permite mover-se, comunicar-se ou alimentar-se sem a ajuda de outros. Mandei notícias, contei sobre mim, sobre o livro que me fez escrever para ela, sobre Nathercinha e Paulo Freire. Mesmo que ela não possa me responder, receberá o envelope, verá a carta, e imagino que alguém abrirá e lerá para ela. Pensei que a materialidade de uma carta, neste caso, pode ter efeitos distintos de outras formas de comunicação que tenho utilizado. Este livro fez com que não desistisse do desejo do encontro com esta amiga, mesmo diante de tantas 
(im)possibilidades. Assim, também desejo que este livro possa estar em sua vida e na dos que por meio de você fazem parte do processo educativo. Que você possa fazer da sua relação com o livro, e com os outros, um processo humano único e singular da casa e do mundo lá fora!

\section{REFERÊNCIA}

LACERDA, Nathercia. A casa e o mundo lá fora: cartas de Paulo Freire para Nathercinha. 1. ed. Rio de Janeiro: Zit, 2016. 